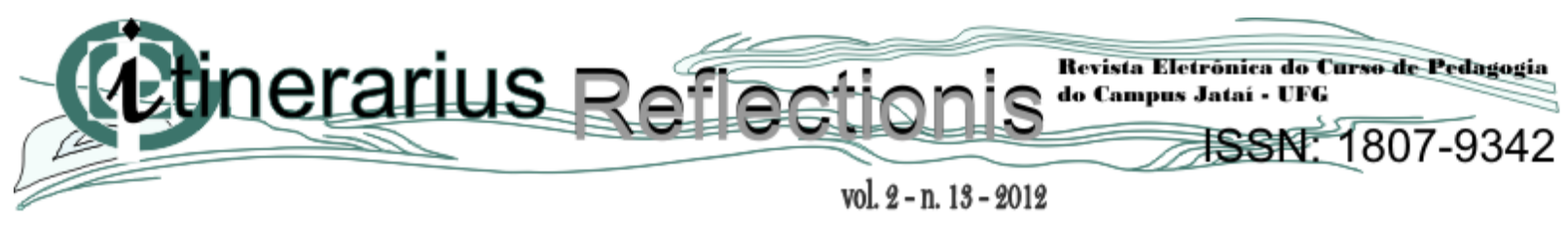

\title{
O QUE VOCÊS GOSTARIAM QUE UM CURRÍCULO DE ARTE CONTEMPLASSE? EXPERIÊNCIAS VIVIDAS, A REORIENTAÇÃO CURRICULAR DO ESTADO DE GOIÁS
}

\author{
Henrique Lima Assis. Centro de Estudo e Pesquisa \\ Ciranda da Arte/Secretaria de Educação de Goiás. \\ Doutorando em Educação Faculdade de \\ Educação/Universidade Estadual de Campinas. \\ FE/UNICAMP. henriquelima2008@gmail.com
}

\begin{abstract}
RESUMO: São apresentadas, neste artigo, algumas reflexões sobre as principais ações referentes à elaboração das Orientações Curriculares para as Artes, na rede estadual de Goiás. Com o objetivo de facilitar as reflexões e as compreensões sobre as experiências vividas pelos 2000 professores de artes da rede estadual de Goiás sobre a sistematização das Orientações, este texto foi dividido em três partes, sendo denominada a primeira de Notas iniciais: os desafios, os conflitos, as aprendizagens que introduz e contextualiza o desafio de sistematizar um documento curricular único para a área e, portanto, apresenta as concepções de currículo, de arte e de educação das artes que sustentaram o percurso. A segunda, Um pouco da história: aparando arestas, minimizando assimetrias, retoma e questiona alguns dos marcos da história da educação das artes no Brasil, cuja finalidade era reconhecer tanto os limites quanto as possibilidades das experiências educativas em arte propostas no passado, para as compreendermos no presente e projetarmos o futuro. E, nesta direção, revisitar a história da educação das artes no Brasil, sobretudo a partir da década de 1970, subsidiou os projetos de elaboração das pistas, dos caminhos, e contribuiu para as escolhas conceituais, metodológicas e práticas que constituem as Orientações Curriculares para as Artes. Estas escolhas estão sintetizadas na terceira parte, denominada As orientações curriculares para as artes: a pista ou as pistas de corrida?
\end{abstract}

Palavras-chave: Educação das Artes. Currículo. Reorientação Curricular.

\begin{abstract}
ABSTARCT: A few reflections about main actions regarding the elaboration of Curriculum Orientations for Arts in the state education system in Goiás, are presented in this paper. In order to facilitate the reflections and the comprehensions of the experiences of 2000 art professors of the state education system in Goiás about the systematization of the Orientations, this paper was divided in three parts. The first one is called Initial Notes: the challenges, conflicts, learning, that introduces and puts into context the challenge of systematizing a unique curricular document for the area and, therefore, it presents the conceptions of curriculum, art and art education in which the course was based. The second part: Some History: trimming off the edges, minimizing asymmetries, reconsiders and questions some of the boundaries of Education History in Brazil, whose objective was to recognize not only the limits but the possibilities of educative experiences in Art suggested in the past, in order to understand them at the present time and to project the future. And, this
\end{abstract}


way, re-visiting the History of Education in Arts in Brazil, most of all since the 70s decade, that supported the elaboration of projects for the paths, the ways, and contributed for the conceptual, methodological and practical choices that constitute the Curriculum Orientations for Arts. These choices are summarized in the third part, called Curricular Orientation for arts: the race track or the race tracks?

Key-words: Art Education. Curriculum. Curriculum re-orientation.

Notas iniciais: os contextos, os desafios, os conflitos, as aprendizagens

A universalização da Educação Básica continua sendo uma das grandes questões do desenvolvimento brasileiro e está inserida no processo de ampliação dos direitos fundamentais e da construção da democracia. Em linhas gerais a educação escolar no Brasil, nas últimas décadas do século $\mathrm{XX}$, foi significativamente ampliada, democratizando, desse modo, o direito de todos à educação.

Em decorrência, a Secretaria de Educação do Estado de Goiás - SEDUC-GO - foi desafiada a pensar e implementar políticas que oportunizassem a criação de práticas educativas eficazes e que motivassem as unidades escolares a se consolidarem como espaços de aprendizagens significativas, garantindo, desse modo, a qualidade do ensino ofertado e a permanência dos estudantes.

Nesta paisagem, uma das políticas implementadas pela SEDUC-GO foi a criação do Programa de Reorientação Curricular, iniciado em 2004 e concluído em 2010, cujos objetivos consistiam em: (a) oferecer subsídios para o fortalecimento do trabalho pedagógico e a melhoria da qualidade das aulas; (b) reduzir as taxas de evasão e de repetência escolares; (c) implementar uma proposta curricular com novos recortes e abordagens de conteúdos e práticas docentes, para que se assumam as atividades específicas de cada área e ligadas à leitura e à escrita, como compromisso de todos e (d) ampliar os espaços de discussão coletiva nas escolas, por meio de grupos de estudos, oficinas e seminários.

Para alcançar tais objetivos, a SEDUC-GO delineou grupos de estudos curriculares, agrupando, em sete pólos, os milhares de professores das várias áreas do conhecimento, modulados nas 1096 escolas, situadas nos 246 municípios do Estado. Assim, em grupos formados por professores dos diversos componentes curriculares, iniciaram-se as 


\section{Ctinerarius Refocionis \\ $\rightarrow 1$}

discussões sobre como desenvolver um trabalho pedagógico que resultasse na melhoria da qualidade das aulas e que reduzisse as taxas de evasão e de repetência nas escolas estaduais. A partir de 2006 esses grupos de estudos foram individualizados por áreas do saber e em 2007 o Centro de Estudo e Pesquisa Ciranda da $\operatorname{Arte}^{1}$ foi convidado a coordenar e sistematizar as discussões em arte.

Posto o desafio: congregar aproximadamente dois mil professores que ensinam artes para ouvir seus desejos, seus sonhos, suas expectativas e, na sequência, sistematizar toda essa carga subjetiva e objetiva em um texto único, para todo o Estado de Goiás. Não foi fácil, foram dias tensos. Para alguns esse documento não deveria existir, pois tolheria a liberdade do professor em relação ao que ele sabia ensinar e ao que seus estudantes queriam aprender. Para outros ele deveria ser o mais prescritivo possível, visto que a maioria dos professores que ministram as disciplinas das artes possui formação em outras áreas, como português, matemática, história e resolveria, também, o velho e polêmico problema da transferência dos estudantes, por motivos pessoais, de uma unidade escolar para outra. Assim, ao se transferirem os estudantes se deparam com conteúdos que eles já estudaram na escola de origem e, na maioria das vezes nos anos anteriores. Os demais professores achavam que o documento - as orientações gerais para as artes - deveria existir sim, pois desenharia uma identidade para a área e, sem prescrições, mais aberto, mais flexível, seria adaptável às inúmeras realidades escolares.

Do debate à construção do texto houve inúmeros conflitos, muitas divergências e confluências, muitas reflexões, ponderações, ajustes, renúncias, aprendizagens. Sem dúvida, uma aprendizagem resultante desse processo e que nos afetou profundamente foi a certificação da coexistência de múltiplas lógicas de relacionar, de ver, de criar, de imaginar, de simbolizar, de investigar, de representar por meio das imagens, dos movimentos, das representações cênicas e dos sons. Nesta perspectiva, pudemos transcender o lido e viver a experiência de que a educação das artes abriga, atualmente, várias concepções e práticas que se entrecruzam, se sobrepõem, se contrapõem, se complementam e, nessa articulação, convive no imaginário social da escola.

\footnotetext{
${ }^{1}$ O Centro de Estudo e Pesquisa Ciranda da Arte é uma unidade da SEDUC-GO que agrega professores de arte, das diferentes áreas da arte, em grupos de estudos e em grupos de produção artística, garantindo, desse modo, a formação continuada em serviço desses docentes.
} 


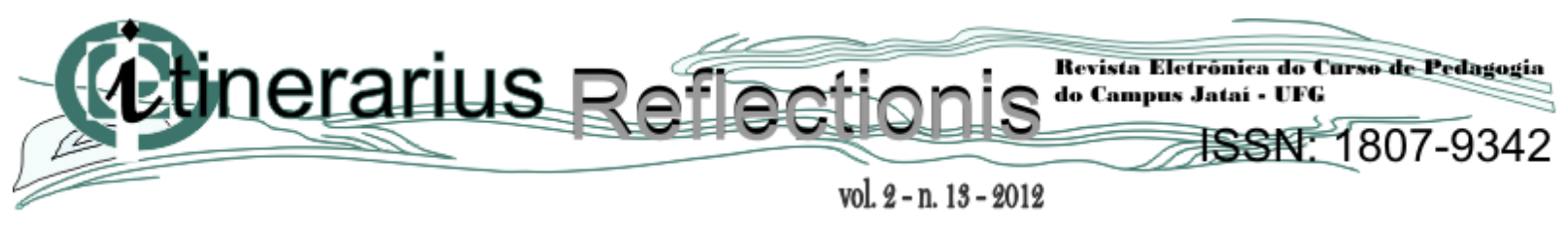

Foram várias as definições e explicações sobre as funções e importância das artes na escola apresentadas pelos grupos de professores. Por exemplo, elas contribuem para o desenvolvimento de capacidades motoras, para a integração social, o reajustamento emocional, para a aquisição cognitiva de conhecimentos relacionados às artes ou a outros conteúdos escolares, o reconhecimento e identificação cultural, entre outras.

Nesta direção, Eça (2009) nos alerta que as funções das artes não devem se reduzir ao desenvolvimento dessas capacidades e nos chama a atenção para o fato de que as artes na escola contribuem, sobretudo, para preservação dos aspectos culturais e estéticos. $\mathrm{Ou}$ seja, as artes na escola devem promover situações em que os estudantes sejam desafiados a se conhecerem ou se reconhecerem como parte integrante de uma cultura, com direitos e deveres, com possibilidades para interagir, manter ou romper com o que está posto, dado e, com e sobre isto, aprender as inúmeras possibilidades de representar e comunicar suas percepções do mundo e projetar sonhos.

Fundamentados, principalmente, em Corazza (2001), Moreira (2001), Sacristãn (1995) e Silva (1999) compreendemos que os apontamentos curriculares são seleções da cultura, que enfatizam, em um universo mais amplo de possibilidades, certos elementos em relação a ou em detrimento de outros. Compreendemos, também, que o currículo é um campo de significação, é território, documento, redes de relações, detém poderes, é trajetória, é autobiografia e, por meio das disputas, tanto individuais quanto coletivas, contribui para a produção de identidades culturais, porquanto não há neutralidade em nenhuma de nossas seleções. Assim, tínhamos consciência de que não podíamos olhar com inocência ou romantismo para as seleções que os currículos operam, para as seleções que iríamos fazer, pois ao enfatizar ou omitir temas, conteúdos, habilidades, saberes, anunciaríamos nossas posições políticas e ideológicas, que sempre atuam a favor de interesses de determinados grupos. Freire (1987) já nos dizia que ensinamos sempre a favor de alguém e contra alguém.

Neste sentido, as ênfases e as omissões curriculares constituem-se no resultado das disputas culturais, dos embates e dos conflitos em torno dos saberes, das habilidades e dos valores que um grupo considera plausíveis de serem ensinados e, consequentemente, aprendidos pelos outros. Ou seja, "ao acolherem certas vozes e ao silenciarem outras, intentase produzir determinadas identidades raciais, sexuais, nacionais, confirmando-se ou não relações de poder hegemônicas" (CANEN \& MOREIRA, 2001, p. 07). 


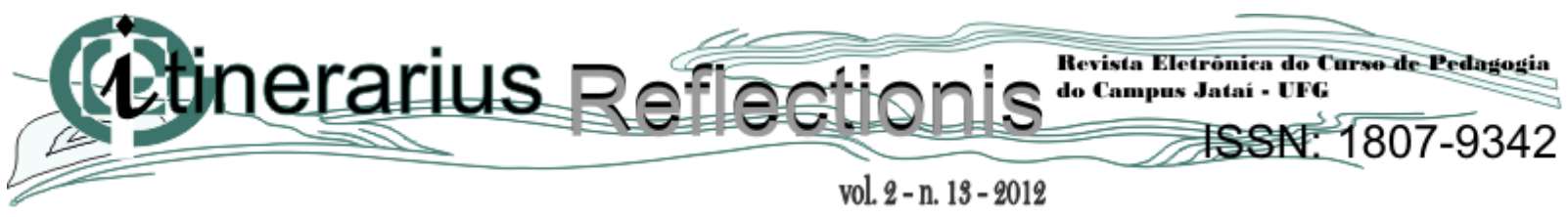

As discussões geradas nos grupos de estudos nos levaram à compreensão de que a educação das artes é também uma seleção da cultura, e assim, apoiados em Silva (1999) pensamos e desejamos que as orientações curriculares para a área das artes sejam capazes de questionar os saberes consensuais e assegurados, conhecidos e assentados e que promovessem estratégias para favorecer e estimular, em relação às identidades culturais, o cruzamento de fronteiras, o impensado, o arriscado, o inexplorado, o ambíguo, o hibrido, o nômade.

Estudar com os pares, compartilhar esperanças, frustrações, incertezas foi um movimento que resultou, como já foi mencionado, em inúmeras aprendizagens e, por conseguinte, em muitas identificações culturais/profissionais. A principal foi a de que estudar currículo significa repensar as relações que ocorrem dentro e fora das salas de aulas, questionando aquilo que é aceito como dado, isto é, algo considerado legítimo e sobre o que não se pergunta de quem é, a quem serve, ou quem o considera válido. Em síntese, aprendemos que o currículo tem o poder para determinar o que se deve processar em sala de aula e diferenciar mundos, sujeitos, conteúdos e práticas que ocorrem ou não nas unidades escolares, conforme assinala Goodson (2003).

Um pouco da história: aparando arestas, minimizando assimetrias

Situados em um contexto pulsante, dinâmico e com várias concepções e práticas para as artes na escola imbuídos do desejo de configurar uma identidade para a área e não uma uniformização, revisitamos alguns marcos da história da educação das artes no Brasil, com o objetivo de reconhecer tanto os limites quanto as possibilidades do passado, para nos compreendermos no presente e projetarmo-nos o futuro, criando escolas que nossos estudantes merecem e que nossa cultura precisa, conforme assinala Eisner (2009).

A ênfase das nossas discussões ocorreu, sobretudo, a partir de 1970. Reconhecíamos que as experimentações estéticas sempre fizeram parte dos cotidianos escolares, porém, de modo espontâneo e sem amparo das legislações específicas à educação. Esse contexto foi modificado com a reformulação da Lei de Diretrizes e Bases da Educação Nacional - LDB/5692 de 1971 que passou a considerar obrigatório o ensino de arte nos $1^{\circ} \mathrm{e}$ $2^{\circ}$ graus, legitimado com o nome de educação artística. 


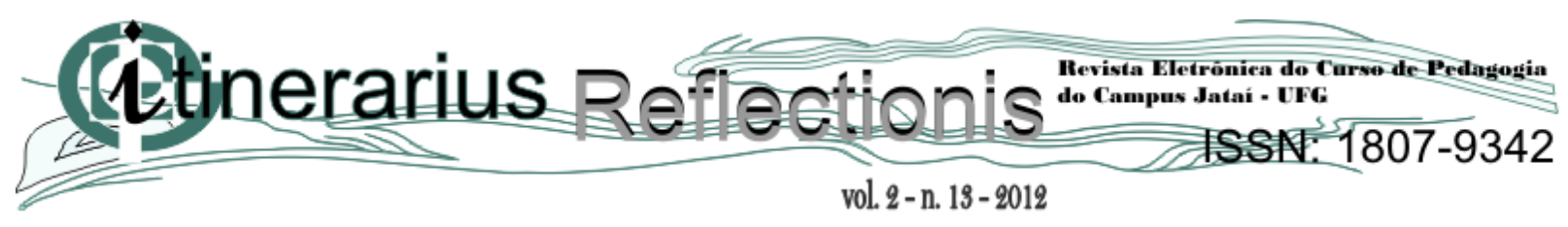

Infelizmente, essa conquista para a educação das artes logo revelou algumas incoerências, fragilidades e entraves. Por exemplo, a falta de professores formados para responder pela obrigatoriedade da disciplina nas centenas de escolas em todo território brasileiro demandou a oferta de cursos, em nível superior, de curta duração, as chamadas licenciaturas curtas. Ou seja, os professores se formaram aligeiradamente e se responsabilizaram pelas artes plásticas, as artes cênicas e a educação musical, com conhecimentos horizontais sobre cada uma delas. Rapidamente, esse ensino caracterizou-se pela polivalência, na qual as áreas das artes deveriam ser ensinadas conjuntamente por um mesmo professor, geralmente de modo superficial e sem compromisso com a efetiva construção de aprendizagens sobre arte.

As décadas de 1980 e 1990 marcaram a organização política e o fortalecimento epistemológico dos professores de arte, mediante as suas participações em congressos, a criação de associações de professores de artes pelo país e a inserção em cursos de pósgraduação. Esse contexto construiu olhares mais reflexivos em torno da docência polivalente, resultando na compreensão de que nesse ambiente, inundado de atividades geralmente desconectadas umas das outras, os estudantes sempre perdiam, pois não havia tempo, nem espaço, nem um fio que conectasse as atividades artísticas propostas. Era um desfile de técnicas, do fazer, do interpretar, do cantar, descontextualizadas das questões culturais, nas dimensões do interagir e refletir, representar, comunicar e projetar sonhos

Um dos fortalecimentos epistemológicos para a educação das artes foi o trabalho que a professora Ana Mae Barbosa desenvolveu no Museu de Arte Contemporânea da Universidade de São Paulo, articulando, a partir de leituras e reflexões sobre de experiências metodológicas dos Estados Unidos, México e Inglaterra, uma orientação para o Brasil que foi denominada de Abordagem Triangular. Amparada em três ações articuladas, livremente e sem ordem pré-estabelecida ou hierarquias valorativas, propunha que as aprendizagens artísticas envolvessem (a) na produção e experimentação expressiva, (b) na leitura da produção de artistas e (c) no conhecimento dos contextos sócio-históricos em que os trabalhos foram produzidos (BARBOSA, 2005).

Em um momento de efervescência, a Abordagem Triangular, sistematizada em várias publicações, e divulgada em eventos da área, ganhou espaço entre a maioria dos professores que se sentiam fragilizados, sem referenciais que os ajudassem a repensar seus 


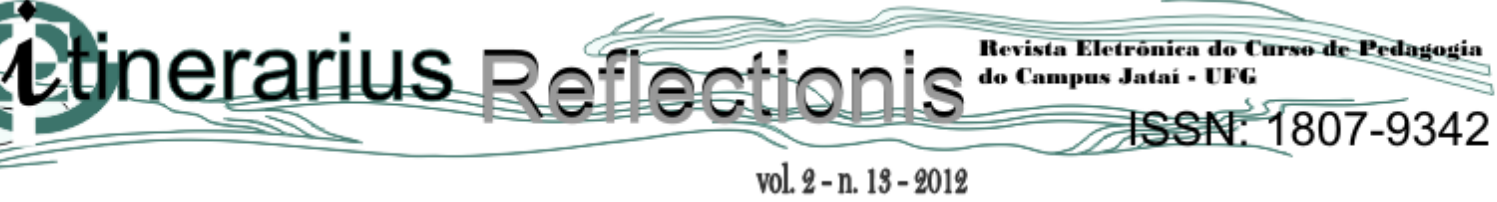

conjuntos de aprendizagens, suas ações educativas, seus projetos de ensino, em suma, seus trabalhos pedagógicos. Outras iniciativas, no sentido de produzir pesquisas na área e divulgar os resultados, produzindo fundamentos mais consistentes e diversificados para a educação das artes no ensino formal, foram motivados. Ao mesmo tempo, multiplicaram-se as ações educativas em instituições legitimadoras das artes: museus, centros culturais, consertos musicais, mostras de dança, de teatro, entre outros.

A reformulação da Lei de Diretrizes e Bases da Educação Nacional/9394 de 1996 consolidou, após muitos debates e embates a respeito da inserção ou não das artes no currículo, sua obrigatoriedade. Sem referência à denominação Educação Artística, mas evocando as artes e a cultura como componentes indispensáveis na formação dos estudantes na Educação Básica. Contudo, ela não explicitou que a aprendizagem artística deveria ser contemplada em todos os níveis e séries da Educação Básica. Nesse sentido, Barbosa (2002) enfatiza que a falta de clareza na referida Lei permite diversas interpretações e práticas: "algumas escolas estão incluindo a Arte apenas numa das séries de cada um desses níveis" (p.13), fragilizando ou até interrompendo os processos cognitivo e afetivo que as artes proporcionam e que são basilares para que os estudantes pensem suas relações consigo, com o outro e com o mundo.

Concomitantemente, foram elaborados os Parâmetros Curriculares Nacionais PCN, trazendo apontamentos para a área das artes no volume 06. Esse documento é considerado um marco, por conferir o mesmo nível de igualdade entre essa disciplina e as demais áreas do currículo e por valorizar a pluralidade cultural, o desenvolvimento da cidadania, a auto-estima do aluno e sua inter-relação com o entorno. Em 2005, os Parâmetros Curriculares do Ensino Médio integraram as artes na área de Linguagens, Códigos e suas Tecnologias, que tem como eixo as faculdades de representação e comunicação. Assim sendo, conhecer os códigos estéticos das linguagens verbal, visual, sonora, corporal e suas hibridizações nos diferentes agrupamentos sociais, bem como os canais tradicionais, tecnológicos e o contexto que lhes confere significado torna possível uma aprendizagem consistente, possibilitando que a recepção desses objetos esteja sempre aliada à produção, à compreensão e à interpretação.

Inúmeras discussões, reflexões e investigações, não só nas artes, mas nas ciências humanas e sociais, especialmente nos estudos culturais, a partir da década de 60 , propiciaram 
o nascimento de um campo interdisciplinar de discussões sobre as imagens na cultura cotidiana, alargando os debates sobre os limites demarcadores das artes visuais e as instituições que as legitimam para o domínio difuso das produções simbólicas que advêm não só dos projetos artísticos, mas também de outras instâncias, tais como a indústria cultural, e a cultura popular. Esse campo, denominado cultura visual, vem acrescentando elementos aos debates correntes em relação às artes e, sobretudo, à educação das artes, ao problematizar e questionar as relações de poder e hierarquias estabelecidas no campo das visualidades, nos processos de legitimação entre as ações de construir, compreender e interpretar nos processos educativos, normatizando ou transgredindo.

Nesse contexto, emergem algumas questões que nos levam a refletir sobre a relevância da educação das artes no contexto escolar e sua significação para os estudantes, ou seja, como os estudantes interagem com as representações simbólicas? Como conceitos e práticas culturais são representados através de imagens, sons, gestos e falas? De que forma essas representações criam e influenciam modos de produzir, apropriar e interpretar o mundo? Que aspectos da diversidade cultural se apresentam nas diferentes formas de interação dos sujeitos com as representações simbólicas? Como tornar significativas essas representações e interações, na educação básica?

Estas reflexões apontam para o entendimento que aprendizagem cultural e estética se entrecruzam, as diferentes configurações expressivas materializadas nas artes visuais, na dança, no teatro e na música constituem-se em conteúdos a serem vividos, discutidos e experimentados no processo de formação nas escolas públicas. E como já foi dito anteriormente, as experiências com as artes privilegiam interações cognitivo-afetivas, que são a base para os sujeitos pensarem suas relações com eles próprios, com o outro e com o mundo.

E, nesta direção, revisitar a história da educação das artes no Brasil a partir da década de 1970, nos forneceu subsídios para pensarmos nas pistas, nos caminhos já percorridos, nos limites e nas possibilidades que eles nos oferecem, auxiliando-nos a tomar decisões, configurando, desse modo, um documento, uma pista, um caminho que apresente as orientações curriculares para as artes. Reflexões sobre essas sistematizações serão apresentadas no tópico que se segue. 


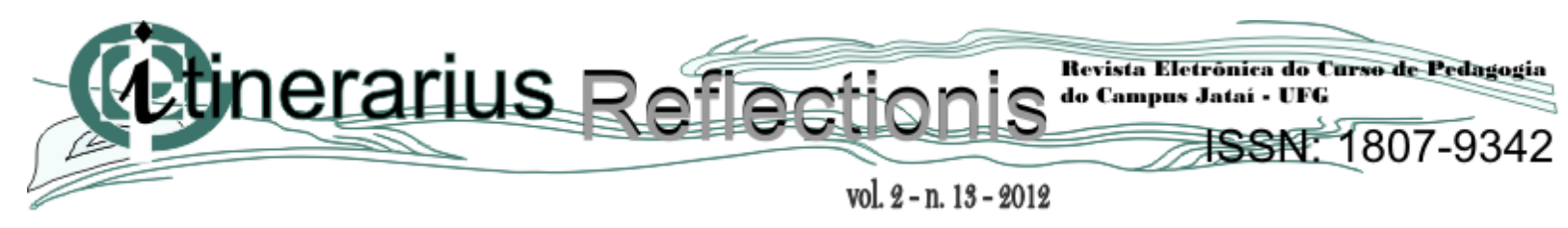

As orientações curriculares para as artes: a pista ou as pistas de corrida?

Ao integrarmos a equipe de Reorientação Curricular para a sistematização das orientações curriculares para a área das artes, entendemos a complexidade deste compromisso e seus desafios, visto ser esta uma ação cultural de organização do que poderia ser trabalhado na rede estadual de educação. O que motivou essa ação pedagógica foi o desejo de contribuir com a educação das artes, na expectativa de minimizar as assimetrias conceituais, metodológicas e práticas que caracterizam as diferentes localidades do Estado, construindo uma identidade para a área.

Motivados pela afirmativa de Silva (1999), na qual os conhecimentos que constituem o currículo estão vitalmente envolvidos naquilo que somos, naquilo que nos tornamos, na nossa identidade e, também, na afirmativa de Tourinho (2008), ressaltando que a participação e intervenção dos professores no processo de negociação e mediação para a construção de currículos são de suma importância, nós, os professores do Ciranda da Arte, percorremos, dezenas de municípios goianos para, mais uma vez, estabelecer interlocuções com os professores que ensinam arte. Desta vez, as reflexões foram mediadas pela indagação: o que vocês gostariam que um currículo de arte contemplasse?

Nesta direção, o "Gráfico 01" apresenta a compilação dos desejos dos professores da Cidade de Aparecida de Goiânia. 


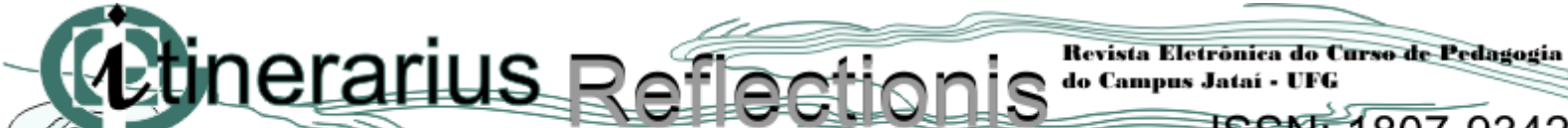 \\ vol. 2-n. $13-2012$

\begin{tabular}{|c|c|c|}
\hline \multicolumn{2}{|c|}{$\begin{array}{c}\text { SUBSECRARIA DE APARECIDA DE GOIÂNIA } \\
\text { CONTEÚDOS: }\end{array}$} \\
\hline Textos reflexivos & Poemas \\
\hline Trabalhos com sucatas & Gravura & Desenho \\
\hline Confecção de painéis & Fotografia & Pintura \\
\hline Dobraduras & Poemas & Leitura de imagens \\
\hline Releitura de imagens & Gravura & Tecnicas de desenho e pintura \\
\hline Técnicas de pintura e colagem & Fotografia & Cinema \\
\hline Confecção de livros & Ponto & Ponto, linha, reta \\
\hline Peças teatrais & Cores & Cultura popular \\
\hline História da arte & Histórias em quadrinhos & Cores da natureza \\
\hline Músicas & Desenho & Cores e formas \\
\hline Datas comemorativas & Releitura & Texturas \\
\hline Cores & Folclore & Recorte e colagem \\
\hline História do cinema e televisão & Sombra e luz & Releitura \\
\hline Reciclagem & Perspectiva & Luz e sombra \\
\hline Dança & Ilustração de texto & Artistas goianos \\
\hline Folclore & Caricatura & Tecnicas de pintura \\
\hline Confecção de brinquedos & Auto retrato & Desenho de observação \\
\hline História da arte & Contador de história & Jogos e brincadeiras \\
\hline História em quadrinhos & Argila & Trabalhos com sucatas \\
\hline Releitura & Linha do tempo & Novas mídias \\
\hline Artistas brasileiros & Simetria & Arte decorativa \\
\hline Intrudução musical & Releitura & Pintura com nanquim \\
\hline Gintura com spray & Publicidade & Auto relevo \\
\hline & Pintura com canudo em tela & Ponto físico, geométrico \\
\hline
\end{tabular}

“Gráfico 01”

Assim, a partir das discussões e do quadro com os conteúdos escritos, desejados pelos grupos de professores, a questão foi respondida e foi possível verificar os anseios, os sonhos, as dificuldades, as contradições, as identificações, os mundos, as práticas, os sujeitos que conduzem a educação da arte em Goiás. Ler, refletir e sistematizar os desejos dos professores nas orientações para área de arte, devolver o texto aos professores, ouvir suas críticas e sugestões e refazer o texto foi uma experiência rica, que nos marcou profundamente e ampliou os modos como pensamos a escola, o currículo, a docência em arte. A seguir, a "Figura 01" apresenta um dos momentos de discussão curricular. 


\section{(titinerarius Re 20}

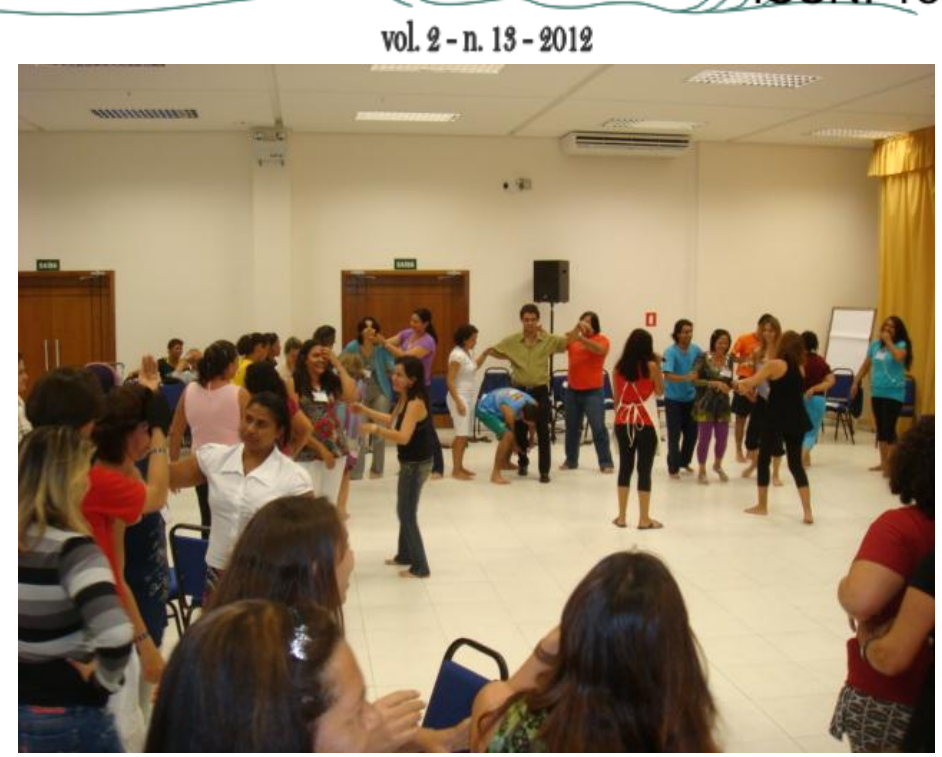

“Figura 01" - Grupo de Estudos Curriculares

As orientações curriculares para a arte no Estado de Goiás não pretendem, e tampouco conseguem, trazer respostas para todas as questões, mas propõem caminhos, levantam e geram questionamentos. Fundamentadas numa perspectiva dialógica, convidam ao desafio de construir uma sociedade mais democrática e visam práticas de justiça social e igualdade de direitos culturais, fortalecendo a liberdade intelectual e a imaginação criativa dos sujeitos. Isso só se torna possível por meio de ações pedagógicas que incluem os sujeitos e lhes permitem estabelecer relações, suscitar suas memórias, rever seus trajetos, pensar no presente, construir posicionamentos e projetos de vida.

As expectativas e os desejos dos professores foram sistematizados em um documento único ${ }^{2}$, mas não polivalente, organizado em tópicos em torno das especificidades das artes visuais, dança, música e teatro. Ou seja, o texto das orientações curriculares é composto, primeiro, por reflexões comuns às quatro áreas, e, em seguida, pelas questões específicas, juntamente com as expectativas de aprendizagem e os mapas curriculares que sintetizam todos os princípios do texto. Para efeito de ilustração, o "Gráfico 02" apresenta o mapa curricular de artes visuais, os mapas das outras áreas podem ser vistos no documento original.

\footnotetext{
${ }^{2}$ Este documento pode ser lido na Página da SEDUC-GO, http://www.see.go.gov.br/ensino/fundamental/.
} 


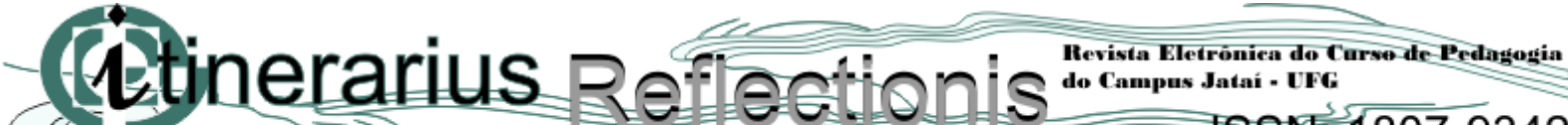 20 ce}

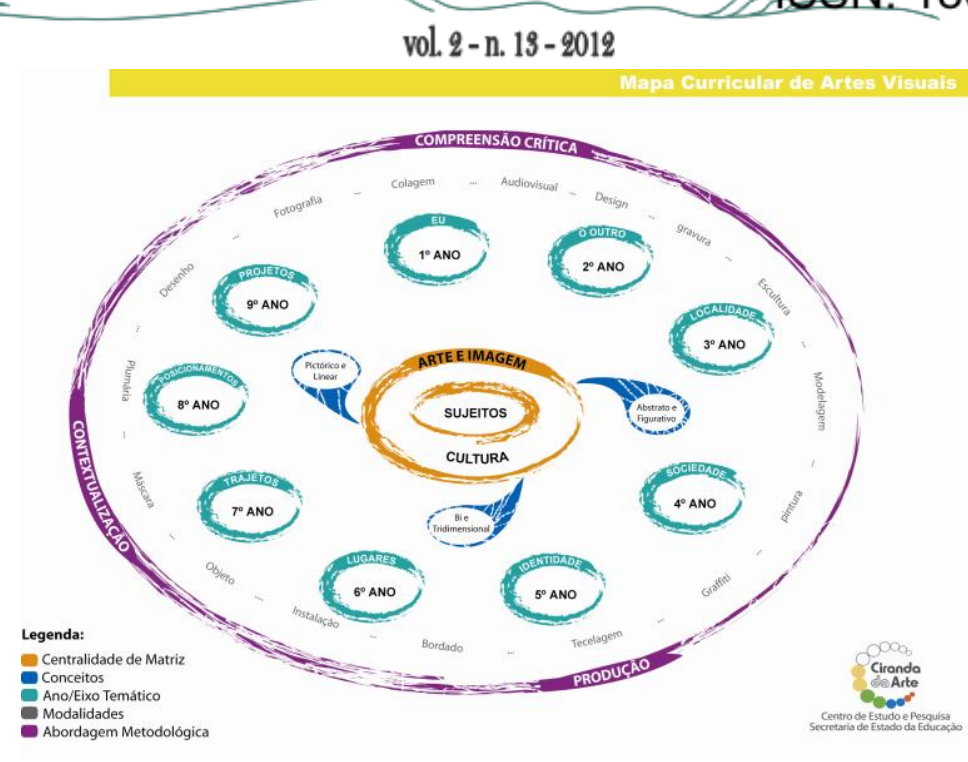

"Gráfico 02"

As orientações curriculares contêm unidade de princípios teórico-metodológicos que propõem orientar os sujeitos a experimentar e vivenciar artefatos e manifestações culturais de grupos e segmentos sociais minoritários, suscitando discussões, reflexões e interpretações críticas em torno de especificidades ligadas ao universo feminino, homossexual, afro-brasileiro, indígena, da classe trabalhadora, da cultura infanto-juvenil e dos sujeitos com necessidades especiais, extrapolando, assim, as aprendizagens para além do universo branco, masculino e europeu, de classe alta, que tradicionalmente dominaram os currículos escolares e, mais especificamente, os temas e focos de estudo das artes.

Vale lembrar que o currículo também é um instrumento que apresenta demandas, necessidades a serem atendidas em negociação entre escolas, comunidade e Estado. Nessas negociações, podemos incluir, além de equipamentos, materiais e espaço físico, que a educação das artes seja garantida em todos os anos da educação básica, com profissionais habilitados em todas as linguagens da arte, reforçando a ação docente especializada. Enfim, numa dimensão ampliada, as orientações curriculares apontam para negociações nas quais as escolas possam se estruturar com salas-ambientes e recursos didático-pedagógicos que contribuam para o desenvolvimento das diferentes ações. 


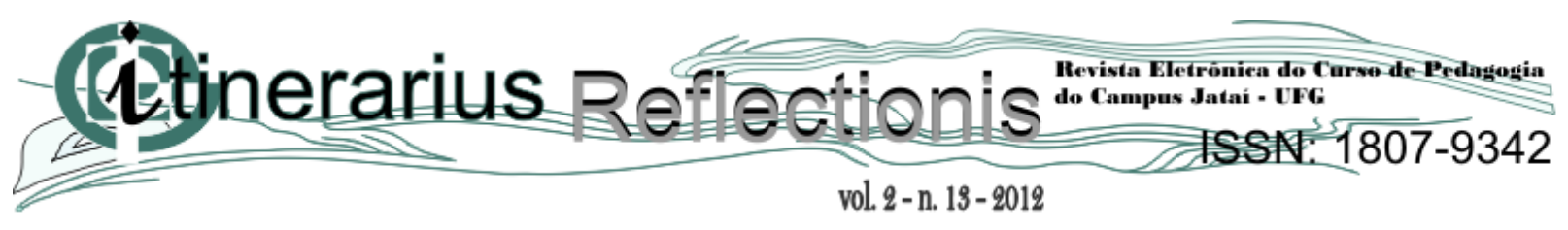

Notas finais: os contextos, os desafios, os conflitos, as aprendizagens, ainda em movimento, pulsando.

Acreditamos que a partir das orientações curriculares, geradas pelas reflexões nos grupos de estudos e nos diálogos constantes com os estudantes, poderemos criar, imaginar e conduzir experiências educativas em arte centradas na pesquisa, na exploração, no distintivo, no metafórico, na valorização do percurso, na reflexão, no singular, no contexto em que estamos inseridos. Dessa forma, poderemos conhecer-nos ou reconhecer-nos como sujeitos integrantes de uma cultura, motivar-nos e perder o medo de ousar, de refletir, de buscar nossos desenhos, nossos movimentos, nossos sons, nossas representações. Em suma, que possamos construir referências de escolas que nossos estudantes procuram, desejam, merecem. Do mesmo modo, que possamos questionar toda sorte de discriminações e silêncios que ocorrem nos espaços escolares, o que implica em problematizar as categorias, as hierarquias e os processos que as tem construído histórica e socialmente. Conforme assinala Eisner (2008, p. 16), "tais aspirações, meus amigos, são estrelas pelas quais vale a pena esticar-se". Que nos estiquemos!

\section{REFERÊNCIAS}

BARBOSA, A. M. A imagem no ensino de arte. São Paulo: Perspectiva, 2005.

CANEN, A.; MOREIRA, A. F. B. (orgs.) Ênfases e omissões no currículo. Campinas, SP: Papirus, 2001.

CORAZZA, S. O que quer um currículo?: pesquisas pós-críticas em Educação. Petrópolis, RJ: Voses, 2001.

EÇA, T. Perspectivar o Futuro: O papel central da arte educação no ensino. In: ASSIS, H. L.; RODRIGUES, E. B. T. (Orgs.) $\mathbf{O}$ ensino das artes visuais: desafios e possibilidades contemporâneas. Goiânia: GRAFSET - Gráfica e Editora Ltda, 2009. 


\section{vol. 2 -n. 13 - 2012}

Revista Eletrónién do Curso de Pedagogia

EISNER, E. O que pode a educação aprender das artes sobre a prática da educação? Disponível em: < http://www.curriculosemfronteiras.org/vol8iss2articles/eisner.pdf >. Acesso em 22/06/2009.

FREIRE, P. Pedagogia do Oprimido. Rio de Janeiro: Paz e Terra, 1987.

GOODSON, I. F. Currículo: teoria e história. (Trad. Attílio Bruneta). Petrópolis: Vozes, 2003.

MOREIRA, A. F. B.; MACEDO, E. F. Em defesa de uma orientação cultural na formação de professores. In: CANEN, Ana; MOREIRA, Antônio F. B. (orgs.) Ênfases e omissões no currículo. Campinas, SP: Papirus, 2001.

SACRISTÁN; J. G. "Currículo e Diversidade Cultural”. In: Territórios Contestados - O currículo e os novos mapas políticos culturais. SILVA, T. T. e MOREIRA, A. F. B. (Org.). Petrópolis: Vozes, 1995.

SILVA, T. T. Documentos de Identidade: uma introdução às teorias do currículo. Belo Horizonte: Editora Autêntica, 1999. 